\title{
Gilza Sandre-Pereira
}

Universidade Federal do Rio de Janeiro

\section{Amamentação e sexualidade}

\begin{abstract}
Resumo: O presente artigo trata a questão da amamentação e sua relação com a sexualidade dentro de uma abordagem antropológica, a partir de entrevistas realizadas com homens e mulheres no Brasil e na França. Na sociedade ocidental moderna, a dupla função - maternal e erótica-dos seios femininos e as representações que homem e mulher fazem da maternidade aparecem como a base de alterações importantes na sexualidade do casal durante o período de aleitamento materno. O leite materno é investido de um forte aspecto simbólico em diferentes culturas, e a amamentação ultrapassa, assim, o quadro biológico e nutricional. O leite, entre outras substâncias corporais, tem um importante papel nas representações do corpo, dando origem a relações de parentesco e a interdições sexuais em diferentes sociedades. A análise das entrevistas com brasileiros e franceses é reveladora igualmente da presença de alguns tabus quando estas duas práticas - sexualidade e amamentação - são colocadas em relação. A reflexão sobre essa questão é fundamental para a discussão das relações homem-mulher no contexto brasileiro atual de incentivo ao aleitamento materno.
\end{abstract}

Palavras-chave: aleitamento materno, sexualidade, maternidade, relação homem-mulher.

Copyright (c) 2003 by Revista Estudos Feministas.

1 Este artigo apresenta alguns dados do estudo comparativo sobre o aleitamento materno no Brasil e na França, realizado no quadro do doutorado em Antropologia Social no Centre d'Anthropologie de Toulouse École des Hautes Études en Sciences Sociales/Université de Toulouse II, sob a direção de Agnès Fine.

\section{Introdução'}

Uma mulher chega com seu bebê para a consulta de puericultura na maternidade. Um detalhe chama a atenção do pediatra: a diferença importante de tamanho entre suas mamas. Uma conversa cuidadosa revelará a origem dessa diferença. Mãe lactante, essa mulher faz uma divisão 'verticalizada' de seu próprio corpo, entre o seio materno, fonte de alimento, e o seio erótico, fonte de prazer sexual. Um seio para o bebê e um seio para o marido.

Essa história, verdadeira, nos coloca diante de uma questão instigante: a relação entre a amamentação e a sexualidade. O aleitamento materno tem sido tema de muitos estudos no Brasil nas duas últimas décadas, a partir de abordagens das mais diversas disciplinas. Assim, é possível facilmente encontrar trabalhos sobre as características bioquímicas do leite humano, sua relação com a saúde da mãe e do bebê, alguns aspectos 
${ }^{2}$ As descobertas de Louis Pasteur
sobre a proliferação dos germes
datam de 1865 e foram
importantes no quadro da
utilização do leite animal para a
alimentação de recém-nascidos. psicológicos dessa prática, e poderíamos ainda citar outras temáticas que têm sido, cada vez mais, alvo de um intenso investimento intelectual de inúmeros pesquisadores. Menos numerosos são os estudos do aleitamento materno na área das ciências humanas, em particular da Antropologia Social, e é dentro dessa abordagem que este artigo pretende tratar a questão da amamentação e sua relação com a sexualidade.

Os dados aqui apresentados são parte de um estudo comparativo sobre a amamentação no Brasil e na França, iniciado em 2000 e em vias de finalização. Durante o século XIX e início do século XX, na Europa e em especial na França, o aleitamento materno e a mortalidade infantil foram alvo de muitos debates que, aliados às descobertas de Pasteur, ${ }^{2}$ estão na base do que se convencionou chamar de 'puericultura científica'. Os intelectuais e os médicos brasileiros foram influenciados por esses debates, de tal forma que se observa um percurso similar da história do aleitamento materno no Brasil e na França durante esse período. Entretanto, hoje esses países diferem grandemente no que concerne às práticas e aos discursos sobre 0 aleitamento materno, o que torna interessante a comparação entre eles. Para estudar esses dois contextos distintos, foi privilegiado o meio social urbano de classe média que apresenta características semelhantes nos dois países, em termos de grau de instrução, de acesso a conhecimentos e de permeabilidade a um discurso medicalizado e 'psicologizado'. Foram realizadas um total de 60 entrevistas não diretivas nos dois países. Foram também utilizados como fonte de informação alguns sites da Internet que possuem fóruns ou listas de discussão sobre temas que envolvem a maternidade ou mais particularmente o aleitamento materno, nos quais é possível acompanhar as 'conversas' dos participantes. Fenômeno recente, esses espaços virtuais de discussão permitem uma observação continuada da circulação de diferentes idéias em torno de um tema e tornam-se assim uma fonte de informação complementar de grande riqueza. Com a intenção de preservar as pessoas cujo discurso me serviu de material de pesquisa, seus nomes e os sites onde elas descreveram suas experiências ou deram suas opiniões não são identificados. Da mesma forma, todos os nomes de informantes são fictícios.

Primeiramente é apresentada uma breve reflexão sobre aspectos simbólicos do leite humano; são apresentados a seguir alguns trabalhos antropológicos sobre interdições sexuais durante o período de aleitamento materno; em seguida, tratar-se-á do seio feminino e suas duas funções - alimentar e erótica; e finalmente serão 
${ }^{3}$ BONTE, 1994.

${ }^{4}$ ARISTOTE, 1961.

\footnotetext{
${ }^{5}$ Roberto LIONETTI, 1988.

${ }^{6}$ Este pedido - leite 'bom' e em abundância - é revelador de uma crença recorrente em diversas sociedades, incluindo a sociedade ocidental moderna, de que existe o leite 'ruim', ou 'fraco', e também da possibilidade de a mulher não possuir leite em quantidade suficiente para alimentar o bebê. Essas idéias estão no discurso de muitas mulheres ao explicar as razões do desmame.
}

analisados os discursos de mulheres e homens sobre o tema em pauta, a partir de entrevistas realizadas no Brasil e na França.

\section{O lelie como substância simbólica}

O leite materno é, além de uma substância produzida pelo corpo, um alimento. Esse aspecto duplo faz com que ele tenha um significado peculiar em relação a outras substâncias corporais (especialmente o sangue e o esperma) nas representações do corpo. Segundo Pierre Bonte, ${ }^{3}$ diversos estudos antropológicos evidenciam que a maior parte das sociedades humanas cria para si respostas a dois tipos de questões recorrentes sobre o leite materno: 1) Qual a natureza dessa substância ou quem, em última instância, provoca essa secreção?; e 2) Que relações são criadas pelo aleitamento, entre a mãe e o filho, em primeira instância, mas também, de uma maneira mais geral, entre aqueles que são associados por essa substância?

Na Antigüidade, Aristóteles propôs uma teoria geral sobre a formação das substâncias corporais que serviu como base para o pensamento ocidental até o século XIX. ${ }^{4}$ A teoria de Aristóteles se relacionava com o calor do corpo humano e tinha como base a idéia de que as substâncias corporais são produzidas a partir de um processo de cocção do sangue dentro do corpo. Para ele, a mulher era considerada como não sendo suficientemente quente para operar a cocção do sangue em esperma. Por outro lado, a partir do sétimo mês de gestação, ela era capaz de operar a cocção do sangue em leite, considerado, por ele, como um produto menos perfeito que o esperma. $O$ homem, quente o suficiente para produzir o esperma, em algumas situações específicas podia também, segundo Aristóteles, produzir leite. Essa antiga proposição teórica foi traduzida, pelo saber popular, em histórias tradicionais que circulam tanto na Europa quanto entre os povos orientais, como a história de Saint Mammant. Conta a tradição que este santo homem encontrou um bebê abandonado e, estando sozinho e não tendo com o quê alimentá-lo, recebeu de Deus a graça de produzir leite para alimentar a pobre criança e salvá-la da morte certa. Esse aleitamento miraculoso transformou Saint Mammant no santo protetor da lactação feminina, cultuado no Oriente bizantino (Constantinopla, Chipre, Grécia) e na Europa (em especial na Itália e na França, mas sendo conhecido também na Espanha e em Portugal). ${ }^{5}$ No século VIII, a catedral de Langres (leste da França) foi consagrada a Saint Mammant, tornando-se o centro espiritual do culto a este santo no Ocidente. A ele recorriam as grávidas, pedindo a graça de ter leite bom e em abundância. ${ }^{6}$ A proteção da 
7 Nilza MEGALE, 1998.

${ }^{8}$ Roy WAGNER, 1983.

${ }^{9}$ Maurice GODELIER, 1982.

${ }^{10}$ Gilbert HERDT, 1984. maternidade e da amamentação é também atribuída à Virgem Maria desde a Idade Média, e uma vasta iconografia da Virgem aleitando surge a partir dessa época. Esse tema é também presente em várias obras sacras no Brasil, sendo uma das mais belas a Nossa Senhora da Lactação, uma efígie barroca que se encontra na Igreja do Carmo, em Belém do Pará.7 Entretanto, ainda que não seja o propósito deste artigo analisar essa questão específica, considero importante destacar o fato de ser atribuído a uma figura masculina o poder de proteger a amamentação. Em relação a isso, poderíamos talvez considerar o pai que dá a mamadeira - tarefa reivindicada por alguns homens - como uma atualização da imagem do homem 'nutriz'.

Vários estudos antropológicos indicam que, entre as sociedades da Nova Guiné, o esperma e o leite materno são freqüentemente conceituados como substâncias homólogas, isto é, a esses dois elementos é atribuída uma origem ou uma função semelhante ou aproximada. A forma diversa com que essas substâncias de origem comum se apresentam deve-se à diferença anatômica entre homem e mulher. Assim, para a sociedade Daribi, o corpo humano é composto de duas redes de 'tubos', sendo uma delas um sistema de passagem do sangue e a outra produtora de esperma ou de leite, conforme o corpo seja masculino ou feminino. ${ }^{8}$ A sociedade Baruya considera o leite materno como esperma transformado em substância nutritiva para os bebês, ${ }^{9}$ e entre os Sambia se diz que "o corpo feminino é como um transformador biológico de esperma". ${ }^{10}$

A relação entre tais substâncias corporais - sangue, especialmente o sangue menstrual, esperma e leite - está na base de explicações simbólicas sobre a procriação, engendra relações de parentesco, orienta as relações homem-mulher e forma o substrato de representações culturais diversas sobre a própria constituição da pessoa e sua identidade social. Dois aspectos dessas representações culturais nos interessam de perto, já que regulam, de um certo modo, a vida sexual de vários grupos sociais. São eles a ligação de parentesco que se forma através do leite materno, e as relações de oposição e de homologia entre o esperma e o leite.

A ligação de parentesco pelo sangue - a consangüinidade - é bastante conhecida. Por outro lado, o parentesco que se forma através do leite também não é fato novo, já tendo sido estudado particularmente no mundo árabe-musulmano, mas também em outras sociedades, como os Ankave da Nova-Guiné. Françoise Héritier, ao falar sobre o parentesco de leite no mundo árabe, faz uma reflexão sobre o 'idêntico' e o 'diferente' e coloca em 
${ }^{11}$ HÉRITIER, 1993.

${ }^{12}$ Soraya ALTORKI, 1980.
${ }^{13}$ HÉRITIER, 1994.

${ }^{14}$ BONTE, 1994. evidência o papel dos fluidos vitais (sangue, esperma, leite) na constituição das relações de parentesco." Para ela, a chave de explicação dos laços que se criam através da amamentação está na idéia de que o leite é produzido a partir do esperma, conforme expresso no provérbio árabe "O leite vem do homem". ${ }^{12}$ Dessa forma, duas pessoas amamentadas pela mesma mulher, mesmo sem terem uma relação de consangüinidade, recebem através do leite a substância paternal e passam a ter uma identidade de substância, tornando-se assim 'idênticas'. A relação sexual entre elas seria então considerada como incestuosa. Mas a interdição sexual ligada ao parentesco de leite entre os árabes não se limita às pessoas amamentadas por uma mesma mulher. Ela se estende a outras pessoas do círculo familiar da lactante (seus ascendentes, por exemplo) e, em uma composição mais sutil, essa interdição existe entre duas pessoas sem laços de consangüinidade, amamentadas cada uma por uma mulher diferente, ambas esposas de um mesmo marido. A coerência dessa interdição se funda na presença da semente de um mesmo homem no leite das duas mulheres, confirmando que o laço de parentesco se produz não através da mulher que amamenta, mas através do fluido masculino do qual o leite é originário. Segundo Héritier, as interdições relativas ao tabu do incesto determinadas pelo parentesco de leite são da mesma ordem que o incesto de segundo tipo. Esta forma de incesto se produz através da relação de dois consangüíneos (por exemplo, duas irmãs ou uma mãe e sua filha) com um mesmo parceiro sexual. Nesses casos, não existe uma relação direta entre as duas irmãs ou entre a mãe e sua filha, mas elas são colocadas em relação através de uma terceira pessoa - o mesmo homem, ao ter relações sexuais sucessivamente com elas, transporta de uma a outra fluidos corporais que concretizam $o$ incesto ao unir duas substâncias 'idênticas'. ${ }^{13}$ A proposição héritiana do incesto de segundo tipo se baseia na circulação dos fluidos de um corpo a outro e na oposição 'idêntico' e 'diferente'.

Ainda nesse tema, para Pierre Bonte, seja entre os Ankave, seja no mundo árabe-muçulmano, o parentesco de leite deve ser considerado nos termos de uma apropriação, pelos homens, do poder feminino da procriação - um trabalho simbólico de reafirmação da dominação masculina, na medida em que o leite, embora produzido pela mulher, é considerado como uma substância masculina, já que sua origem é o esperma. O parentesco de leite reafirmaria, assim, a preeminência da participação paterna na genealogia da criança. ${ }^{14}$

O leite, entre outras substâncias corporais, é investido de um forte aspecto simbólico em diferentes culturas, e a 
${ }^{15}$ Pascale BONNEMÈRE, 1990.

${ }^{16}$ BLEDSOE, 1987.

${ }^{17}$ BONTE, 1994. amamentação ultrapassa, assim, de forma evidente, o quadro biológico e nutricional.

\section{O aleitamento materno e as interdições sexuais}

Mesmo quando o aleitamento não é concebido em termos da criação de uma ligação de parentesco, o que ocasionaria por si só interdições no plano sexual, a relação entre o esperma e o leite está na origem de interdições sexuais em muitas sociedades.

Os membros da sociedade Mae-Enga, da NovaGuiné, conceituam o leite materno e o esperma como substâncias opostas e que, portanto, não podem ser colocadas em contato. Eles consideram que durante $o$ ato sexual o esperma pode contaminar o leite; desse modo, nessa sociedade as relações sexuais são proibidas durante todo o período da amamentação. ${ }^{15} \mathrm{~A}$ relação entre o leite materno e o esperma também é encontrada entre os Mende na Serra Leoa, África, segundo o trabalho de Caroline Bledsoe. ${ }^{16} \mathrm{Na}$ sociedade Mende, as relações sexuais são fortemente proibidas durante a amamentação para evitar que o esperma do pai se misture ao leite da mãe, o que provocaria a morte da criança. Nesse caso, esperma e leite não seriam substâncias opostas, como para os Mae-Enga, mas homólogas. Como diz Pierre Bonte, a criança, tendo sido já formada pelo esperma do pai no útero materno, sofreria de uma espécie de 'excesso de identidade' pela presença do esperma no leite. ${ }^{17}$ Entre os Mende, a abstinência sexual deve ser seguida durante todo o tempo que dure a amamentação, e o desmame acontece, em geral, apenas quando a criança começa a andar. Um detalhe a ser destacado na análise de Caroline Bledsoe é que a proibição da prática sexual se limita às mulheres. A poligamia é culturalmente aceita e, mesmo que o homem não tenha oficialmente outra ou outras esposas, ele pode satisfazer seus desejos sexuais fora de casa, sem que isso implique um prejuízo para seu filho amamentado. Pode-se imaginar que essa não é uma situação muito confortável para as mulheres, mesmo na ocorrência da poligamia, uma vez que, não sendo a mulher sexualmente disponível, ela perde a preferência aos olhos de seu esposo, o que pode implicar a perda eventual de certas vantagens no âmbito da família. Uma outra questão que se coloca é que a saúde da criança pode ser vista como um indicador moral da mãe: se a criança fica doente, com diarréia e vômitos, isso é tido como uma confirmação de que a mãe não obedeceu à proibição e teve relações sexuais no período da amamentação, o que é socialmente muito mal 
${ }^{18}$ RIBEIRO, 1996.

${ }^{19}$ BADINTER, 1980.

\footnotetext{
${ }^{20}$ Para Santo Agostinho, a criança é concebida como símbolo da força do mal, um ser imperfeito, esmagado pelo peso do pecado original; para Descartes, ela é vista como fraqueza do espírito a infância é o período da vida em que a faculdade de conhecer, o entendimento, está sob a total dependência do corpo.

21 Gilberto FREYRE, 1978, e Elizabeth MAGALHÃES e Sonia Maria GIACOMINI, 1983.
}

visto, e torna a mãe 'culpada' pelos problemas de saúde do filho.

O tabu sexual durante o aleitamento materno está presente também entre algumas tribos indígenas brasileiras na forma do ritual da 'covada'. Darcy Ribeiro, por exemplo, faz referência a esse ritual entre os índios Urubus-Kaapor do Maranhão. ${ }^{18}$ Ele relata que a abstinência sexual deve ser mantida até a cerimônia de 'batismo', quando o pai dá um nome à criança, ritual que acontece quando a criança começa a sentar. Darcy Ribeiro acrescenta que, em geral, os casais Urubus-Kaapor continuam a evitar as relações sexuais durante um ano ou mais, ou seja, o tempo que dura a amamentação até o desmame. Durante esse período, se ocorre uma relação sexual, a mulher afasta o homem antes da ejaculação (coito interrompido), de forma a evitar que esperma e leite se misturem. Diferentemente dos Mende da África, entre os Urubus-Kaapor são os dois - pai e mãeque participam do tabu sexual pós-parto.

A interdição sexual no período de amamentação aparece também na Europa, particularmente na França dos séculos XVII e XVIII. A medicina da época, herdeira do pensamento aristotélico, defendia a idéia segundo a qual o esperma contaminava o leite materno, que se tornava azedo, o que colocava em perigo a vida do bebê. Por essa razão, os médicos prescreviam a abstinência sexual durante o período da amamentação. Essa prescrição, segundo Elisabeth Badinter, seria um dos motivos da prática de contratar amas-de-leite mercenárias. ${ }^{19} \mathrm{~A}$ utilização das amas-de-leite foi uma prática generalizada na França, mas é importante ter em conta a existência de uma diferenciação social ao colocar tal prática em relação com a sexualidade. O tabu sexual talvez fosse menos importante que a possibilidade de a mãe continuar trabalhando para ganhar o pão diário, na escolha do modo de alimentação do bebê entre as famílias dos meios sociais menos favorecidos. Já para as mulheres das classes altas essa prática de contratar uma ama-de-leite se inseria claramente nos valores sociais dominantes da época: a prioridade dada aos interesses masculinos (inclusive sexuais); a concepção da infância segundo os pensamentos de Santo Agostinho e de Descartes; ${ }^{20}$ e o papel desempenhado pela mulher na vida social da época, e do qual ela não poderia nem desejava abrir mão. O Brasil também conheceu a prática da utilização de amas-de-leite na alimentação dos bebês, prática esta trazida de Portugal durante a colonização. Em geral, cabia às escravas negras o serviço de ama-de-leite, criando-se assim a figura da mãe preta, tão presente na literatura brasileira. ${ }^{21} \mathrm{~A}$ utilização de amas-de-leite, que originalmente era uma prática das famílias abastadas, 
${ }^{22}$ Antônio Augusto SILVA, 1990.

${ }^{23}$ FINE, 1994.

${ }^{24}$ Essa indicação valia também para o aquecimento do corpo produzido pelo trabalho, ou seja, a mãe também não deveria amamentar logo que chegasse do trabalho, sem se 'refrescar'.

${ }^{25}$ Essa confusão entre natureza e cultura em termos de 'animal mamífero' pode ser muito bem percebida na publicidade veiculada em meados da década de 1990, no Brasil, pela Parmalat Indústria e Comércio de Laticínios Ltda., que utilizou como mote a frase "Porque nós somos mamíferos". De fato, "nós somos mamíferos", e o leite é nosso primeiro alimento. Mas... qual leite? A idéia da natureza que a frase exprime se mistura com a imagem das crianças fantasiadas de animais mamíferos, tomando o leite de vaca industrializado da marca Parmalat, o que nos traz de volta ao mundo da cultura.

${ }^{26} \mathrm{~A}$ caridade romana é uma expressão conhecida da iconografia, sendo tema de diversas pinturas do Renascimento. A caridade romana é representada por uma jovem amamentando um homem idoso. Essa representação se deve a uma lenda relatada por Valerio Massimo (15 a.C. -35 a.D.) na obra Factorum et dictorum memorabilium libri (Fatos e ditos memoráveis), que aborda fatos classificados em termos de vícios e virtudes. Na virtude 'caridade' é relatada a história da jovem Grecque Pero, que salva a vida de seu pai Cimon, condenado a morrer de fome na prisão, ao amamentá-lo durante as visitas ao prisioneiro. O quadro La charité romaine, de Francesco Primaticcio (1504-1570), encontrase no Cabinet des Dessins do Musée du Louvre em Paris.

${ }^{27}$ FORD e BEACH, 1951. Este famoso livro do antropólogo Clellan S. Ford e do psicólogo Frank A. Beach Patterns of Sexual Behavior - tornouse um clássico dos estudos sobre sexualidade. O livro explorou o comportamento sexual de humanos e animais, a partir de três perspectivas diferentes: biológica, passa a ser uma demanda também da classe média urbana a partir do século XIX, o que pode ser atestado pela quantidade importante de anúncios na imprensa oferecendo ou procurando o serviço de amas-de-leite de aluguel, e também pela presença constante dessa questão no discurso médico da época. ${ }^{22}$

Um outro exemplo em que as relações sexuais durante o período de aleitamento materno são, se não proibidas, ao menos 'bem enquadradas' é encontrado no trabalho de Agnès Fine sobre as representações do leite materno entre as mulheres idosas do Pays de Sault, no sul da França. ${ }^{23}$ Nesse caso não se trata de uma representação das substâncias corporais que ligue diretamente o esperma e o sangue, mas sim de uma representação das alterações das substâncias pelo calor, o que nos leva mais uma vez às teorias aristotélicas. De fato, Agnès Fine, em seu artigo, demonstra a convergência dos saberes médico e popular sobre o leite materno. A idéia de que o leite da mulher, em conseqüência do aquecimento do corpo feminino, pode se tornar um 'leite ruim', um verdadeiro veneno que pode matar a criança, era compartilhada por mulheres e médicos na primeira metade do século XX. Assim, uma das circunstâncias que poderia prejudicar o leite materno seria a vivência de paixões eróticas pela mulher, pois estas 'aquecem o sangue'. A mulher não deveria, por essa razão, amamentar o bebê logo após uma relação sexual - era preciso esperar que o sangue (e o leite) 'esfrie'. ${ }^{24}$ É evidente que a vida conjugal será fortemente alterada diante de cuidados e preocupações desse tipo.

\section{Seio de mulher, seio de mãe}

Essa dupla representação dessa parte específica do corpo feminino se insere na tradicional oposição antropológica entre natureza e cultura. Considerado em termos da natureza, o ser humano é classificado como um animal mamífero e, portanto, as mamas das 'fêmeas' humanas têm uma função específica, ligada à alimentação da sua 'cria'. ${ }^{25}$ Mas o homo sapiens é um animal cultural, e no mundo da cultura o seio feminino pode perder a preeminência biológica de sua função e tornar-se a base de diferentes representações, como a caridade, ${ }^{26}$ e aquela que nos interessa de perto neste artigo, o erotismo. O seio pode ser ou não erótico e ligado à sexualidade segundo diferentes culturas. Segundo Clellan Ford e Frank Beach, ${ }^{27}$ que estudaram as práticas sexuais em 190 diferentes culturas no mundo, somente 13 entre elas conferiam um valor erótico aos seios, tendo seu aspecto físico um importante papel para a atração sexual masculina e sendo sua estimulação uma parte do ato sexual. 
psicológica e sociológica Certamente, o mundo é hoje bem diferente depois de passado meio século, mas a compreensão da existência de uma diversidade de comportamentos e representações sexuais possíveis, desvelada por esse trabalho de antropologia comparativa, permanece como uma importante referência. No que se refere especificamente à percepção erótica do seio feminino, é possível mesmo imaginar que tal representação seja hoje mais difundida e presente em um número maior de culturas. ${ }^{28}$ BOLOGNE, 1986.

${ }^{29}$ Até o século XVII, no Ocidente, o casamento estava fundado não sobre o amor, mas sobre interesses econômicos e sociais. Isso não significa que o amor era sempre ausente, mas esse sentimento não era necessário à existência nem ao equilíbrio da família. Uma análise das mudanças no casamento a partir do surgimento do amor romântico, que passa a fundar o casamento sobre uma base afetiva, pode ser encontrada em diversas obras, como Edward SHORTER, 1995, ou Jean-Louis FLANDRIN, 1981.

${ }^{30}$ THIS, 1980, p. 121.

${ }^{31}$ A instituição da mulher cristã.

${ }^{32}$ VIVES citado por BADINTER, 1980 , p. 72 .
Na cultura ocidental o seio foi inscrito durante muito tempo em uma percepção funcional alimentar, sendo muito recente a erotização dessa parte do corpo feminino. Ao traçar a história da nudez, Jean-Claude Bologne mostrou que, em diferentes sociedades e em épocas diversas, certas partes dos corpos femininos e masculinos, mesmo as mais íntimas, podiam ser mostradas. ${ }^{28}$ Segundo esse autor, o significado do olhar lançado sobre a nudez mudou muito ao longo dos séculos no Ocidente, e foi apenas no final da Idade Média que a nudez feminina e a visão do nu passaram a ser identificadas com o desejo e a ter a conotação erótica que conhecemos hoje. O seio, no entanto, permanece discreto até o surgimento do 'amor romântico', no século XVIII. Coincide com essa mudança o nascimento da forma moderna do sentimento conjugal. ${ }^{29}$ Relação de sedução e de amor, o casamento se insere na perspectiva do desejo provocado pela visão do corpo feminino, que se mostra de uma certa maneira e seduz. $E$ são os seios que atiram o olhar e fixam a atenção nesse jogo de sedução. As alterações que aparecem em termos da maneira de se vestir evidenciam essas mudanças, através do surgimento dos vestidos com decotes sensuais que valorizam os seios sem os desvelar completamente.

Na sociedade ocidental moderna, a função estética do corpo, e do seio, em particular, se hipertrofiou. Sua forma, seu volume, sua consistência devem se alinhar a um modelo preciso. Nesse contexto, o seio é percebido primeiro e antes de tudo como um órgão sexual, de grande apelo erótico. Mas a utilização dos seios na sua função biológica da amamentação não está completamente desligada da possibilidade de uma experiência sensual. Nas palavras do psicanalista francês Bernard This, "Aquelas mulheres que amamentaram seus filhos com prazer sabem que uma mulher pode chegar ao orgasmo quando a criança mama. Mas, silêncio, os homens não querem saber! O prazer deve aparecer apenas nos braços do amante?" 30

Não é recente a idéia de que a prática da amamentação tem implicações com a sexualidade. No século XVI, o humanista e filósofo espanhol Juan Luis Vives, na sua obra De institutione feminae christianae ${ }^{31}$ (1523), advertia que "As delícias são o que mais debilita o corpo; por isso, as mães perdem os filhos quando os amamentam voluptuosamente", em uma alusão ao prazer sentido pela mãe e pela criança na amamentação - um prazer ilícito que a mãe se proporciona e que causaria a perda moral da criança. ${ }^{32}$ Mais tarde, na França do século XVIII, quando a relação entre a mortalidade infantil e a prática de enviar os bebês para serem amamentados por amas-de-leite mercenárias estava sendo demonstrada, o médico Jean- 
33 DES-ESSARTZ, 1799 , p. 366 , citado por Catherine ROLLET e Marie-France MOREL, 2000, p. 106.

${ }^{34}$ FREUD, 1997, p. 60.

${ }^{35}$ FREUD, 1997, p. 100.

${ }^{36}$ A percepção de um componente sexual na relação entre mãe e filho é abordada também por outros autores, como Ellis HAVELOCK, 1913.
Claude Des-Essartz procura encorajar as mulheres a amamentarem elas mesmas seus filhos, através do testemunho de uma jovem mãe sobre suas sensações físicas ao colocar o filho ao seio pela primeira vez: "É difícil - diz ela - de explicar o que se passou comigo, eu senti uma comoção que eu só posso comparar àquela que é produzida por uma centelha elétrica; tão intensa que ela, ela me ergueu e me fez me aproximar mais do meu filho, ela logo se espalhou por todo o meu corpo produzindo um calor delicioso, ao qual sucedeu a calma de uma volúpia inexprimível, quando meu filho abocanhou meu mamilo e fez sair o licor que a natureza e o meu carinho lhe destinavam." ${ }^{33}$ Uma descrição de prazer semelhante a de um orgasmo.

No início do século XX os manuais de puericultura, bastante numerosos a partir do final do século anterior com o advento da puericultura científica da era pasteuriana, não mencionavam mais o prazer ao falar sobre o aleitamento materno. Aparentemente, só a psicanálise se referia à existência de um tal prazer, chamando a atenção para o fato de que a amamentação é uma relação sexualizada, prazerosa para a mãe e psicologicamente fundadora para o bebê. A sexualidade associada à amamentação foi apontada por Freud, ao falar sobre a sexualidade infantil: "Quem já viu uma criança saciada recuar do peito e cair no sono, com as faces coradas e um sorriso beatífico, há de dizer a si mesmo que essa imagem persiste também como norma da expressão da satisfação sexual em épocas posteriores da vida." ${ }^{34}$ Mas o ato de oferecer o seio, considerado como uma zona erógena, para o bebê sugar também é compreendido por Freud como um ato de significação sensual para a mulher. Segundo esse autor, a mãe olha para a criança "com os sentimentos derivados de sua própria vida sexual: ela a acaricia, beija e embala, e é perfeitamente claro que a trata como um substitutivo de um objeto sexual plenamente legítimo." ${ }^{35}$ Tais afirmativas tendem a chocar a princípio e serem mesmo consideradas sacrílegas - e Freud faz referência a esse fato -, uma vez que se colocam em frontal oposição à imagem do amor maternal assexuado, 'puro'. ${ }^{36}$

De acordo com os depoimentos de meus informantes, as representações específicas sobre o seio têm um papel importante na sexualidade durante o período da amamentação. O seio maternal e o seio erótico podem ou não ocupar o mesmo espaço físico, engendrando diferentes possibilidades de experiências de acordo com a maneira como cada indivíduo resolve essa aparente dicotomia. 


\section{A amamentação e a sexualidade nas palavras de homens e mulheres}

Ao trabalhar com dois universos distintos, somos tentados a ver em primeiro plano as diferenças que os separam. As especificidades dos dois grupos de informantes - brasileiros e franceses - existem, mas, no que concerne ao tema tratado neste artigo, são as semelhanças entre os discursos que se impõem como objeto de análise. Ao observar os discursos de meus informantes sobre a amamentação, a questão da sexualidade, e dentro dela o dualismo do seio maternal e do seio erótico, aparece de

${ }^{37}$ Pude observar, no discurso da quase totalidade de minhas informantes, a existência de um certo 'ideal de boa mãe' que se aproxima do discurso sobre a maternidade iniciado na Europa no século XVIII, e que propõe as noções de 'sacralidade' e de 'santidade' do papel de mãe. É certo que o movimento feminista contribuiu para uma 'dessacralização' da maternidade, mas ainda hoje, mesmo quando as mulheres rejeitam racionalmente esse modelo de 'maternidade sagrada', ele parece permanecer e se revela nas tensões que podem ser observadas nas representações dos meus informantes.

${ }^{38}$ Para este artigo, a ênfase foi colocada naqueles discursos de minhas informantes em que a amamentação aparece como uma experiência prazerosa. Não podemos negar, no entanto, que nem todas as mulheres vivem a amamentação da mesma maneira. A ocorrência de problemas, como rachaduras no mamilo por exemplo, pode fazer com que a mulher associe o aleitamento materno a uma experiência dolorosa e desconfortável. Por outro lado, algumas das minhas informantes referiram a relação entre a dor dos seios cheios de leite e o alívio proporcionado pela mamada como um momento especial de prazer. Essa percepção sugere a existência de outras possibilidades de análise que serão levadas em conta na continuidade desta pesquisa. forma marcante nas entrevistas realizadas com mulheres $e$ homens, seja no Brasil, seja na França. A percepção do seio maternal evidencia, de acordo com os depoimentos de meus informantes, a persistência de uma noção 'sacralizada' da maternidade na construção da identidade feminina, ${ }^{37}$ mas essa questão não é desenvolvida neste artigo, embora apareçam aqui e ali alguns pontos relativos a esse tema na discussão das entrevistas. Na apresentação da análise do discurso de meus informantes, portanto, são apresentados especificamente os pontos que se referem à relação entre a amamentação e a sexualidade. ${ }^{38}$

$\mathrm{Na}$ análise das entrevistas, foram definidos quatro pontos a partir dos quais pode-se discutir a relação entre a amamentação e a sexualidade: a baixa da libido nas mulheres após o parto; o 'tabu do seio materno'; o tabu do incesto; e, finalmente, o 'sono compartilhado'. Embora sejam muito ligados entre si, esses quatro pontos são alvo de reflexões em separado, tendo em vista uma melhor compreensão dos fenômenos a que se referem.

\section{A baixa da libido nas mulheres após o parto}

Quando essa questão específica é abordada por minhas informantes, nota-se o recurso freqüente a expressões oriundas do saber médico: "tem o problema dos hormônios". As modificações hormonais que ocorrem na gestação, parto e lactação são apontadas pelo saber médico como a causa dessa baixa de libido. Verifica-se após o parto uma baixa das taxas de estrogênios e de progesterona, e paralelamente um aumento das taxas de prolactina. Segundo o conhecimento científico no campo da endocrinologia, os hormônios estrogênios favorecem a receptividade sexual, enquanto a prolactina, necessária à produção do leite, a inibe. Essas questões são certamente importantes e devem ser levadas em conta; contudo, elas não explicam a totalidade do fenômeno. Mesmo na literatura médica existem autores que exprimem um ponto de vista menos determinista no que diz respeito à 
${ }^{39}$ PASINI E ABRAHAM, 1974, p. 286.

interferência hormonal sobre o desejo sexual no pós-parto. Segundo Willy Pasini e George Abraham, "Se é comprovado que existe uma importante modificação hormonal no pósparto, é muito menos demonstrável sua relação com o comportamento sexual." 39 Não é objetivo deste artigo discutir o mérito das explicações médico-científicas sobre a queda da libido no pós-parto, mas evidenciar as diferentes maneiras como as mulheres vivem e explicam esse fenômeno.

Segundo minhas informantes, o retorno a uma vida sexualmente ativa com o companheiro costuma ser alvo de negociações, nem sempre satisfatórias para ambas as partes. Nesse sentido, não são raros os relatos sobre a dedicação exclusiva da mãe ao bebê, colocando o companheiro em segundo plano, o que é sentido por muitos homens como uma rejeição. Cito aqui, por exemplo, as

${ }^{40}$ As entrevistas em francês foram traduzidas por mim. palavras de Sylvie, ${ }^{40}$ uma jovem francesa de 25 anos, dona de casa:

Eu não tinha desejo sexual durante os dois ou três primeiros meses e... É como se meu marido não fosse capaz de todo o carinho, do toque pele-a-pele, sabe! Enfim... da carícia, de coisas assim... Enquanto que eu tinha encontrado tudo isso nele. [Ela mostra seu bebê e ri timidamente.] E depois, efetivamente, esse problema do desejo sexual começou a aparecer. E foi meu marido quem falou. Ele dizia: - Escuta, e eu?

A recusa de restabelecer uma vida sexual com seu marido após o parto, nesse caso, é explicitamente ligada a uma relação plenamente satisfatória com o filho, e foi somente depois das queixas do marido que, ao final de três meses, Sylvie aceitou novamente ter relações sexuais. Nesse mesmo sentido, Lúcia, uma arquiteta brasileira de 44 anos, afirma:

Fisicamente, é suficiente para mim ficar com minha filha. É diferente do [prazer] sexual, mas é uma energia física.

A baixa de libido pode trazer importantes conseqüências para a relação do casal, e algumas mulheres chegam mesmo a radicalizar, dizendo que seria normal que o homem fosse buscar sua satisfação sexual fora de casa para que a mãe possa ficar em paz com seu bebê e chamando esse arranjo de 'norma biológica'.

\section{O 'tabu do seio materno'}

Uma segunda questão na relação entre a amamentação e a sexualidade é o dualismo seio maternal/ seio erótico, e a esse respeito meus informantes são numerosos em confirmar, nas suas práticas, a existência de 
uma espécie de 'proibição' de tocar o seio maternal. Esse fenômeno eu chamo de 'tabu do seio materno'.

Na verdade, essa foi a questão que originou esta pesquisa antropológica sobre o aleitamento materno, a partir da história que introduz este artigo, na qual se observa uma divisão 'verticalizada' do corpo feminino separando cada seio para uma função distinta: erótica ou maternal. Existem outros casos em que a mulher amamenta apenas com um dos seios, porém essa história é a única de que tenho conhecimento em que a motivação derivada dos papéis materno e erótico dos seios é bem estabelecida e consciente para a mulher em questão. É também o único caso em que a divisão simbólica do corpo feminino é feita com uma separação 'na vertical'. Por outro lado, os dados oriundos das minhas entrevistas revelam a existência de vários casos em que a idéia de divisão do corpo é evidenciada - uma divisão 'horizontalizada', entre a metade inferior, sexual, e a metade superior, maternal e reservada à função alimentar.

Em várias entrevistas, tanto com homens quanto com mulheres, eu ouvi relatos sobre o tabu de se olhar sexualmente para o seio maternal. Celso, militar da reserva e advogado brasileiro de 42 anos, descreve assim seus sentimentos quando vê uma mulher amamentando:

Eu acho bonito. Eu vejo como uma coisa mais pura isso aí. (...) Pô, uma mãe dando o peito pro filho, eu não consigo ver isso como uma coisa... de um lado erótico. (...) Eu vejo uma mulher na rua dando o peito, isso me desperta uma ternura por aquilo, uma coisa meio sagrada, sabe.

Mais ou menos no mesmo registro, François, professor de sociologia, 34 anos, francês, também explicita no seu discurso a existência dessas duas dimensões - maternal e erótica - dos seios:

Eu creio que o fato de ver o bebê... perturba a dimensão erótica. Mesmo se é um seio, ele não tem mais um efeito provocador de... de alguma coisa. (...) A presença da criança ao seio... é um outro contexto, o seio muda de forma... é uma forma simbólica, ele entra em um outro registro... e daí não é mais a mesma coisa, não dá pra ver o seio da mesma maneira.

Os homens dizem, em geral: "o peito é sagrado" ou "é diferente, quando a mulher está amamentando, não dá pra olhar praquilo ali e ter desejo, né? A mulher ali, com o bebê... o homem que pensa assim é um tarado!". Já as mulheres relatam: "ele não toca não, ele respeita". Isso traz subjacente duas concepções características da tradição judaico-cristã: a idéia da maternidade sagrada e de que o seio maternal torna-se intocável, perdendo simbolicamente 
${ }^{41}$ La Leche League é uma instituição não governamental internacional de promoção e apoio ao aleitamento materno. Ela foi fundada por sete mães do subúrbio de Chicago, EUA, em 1956, e funciona hoje em mais de 65 países. As 'líderes' da La Leche League são mães que viveram uma experiência bem-sucedida de amamentação e trabalham como voluntárias para ajudar outras mães a amamentar, através do apoio 'mãe-a-mãe'. Essa instituição está presente na França, com grupos de mães espalhados em todo o território. No Brasil existe apenas um grupo de mães ligado à La Leche League International, em Maceió. seu valor erótico; e a idéia de que o sexo seria 'nãosagrado', impuro, desrespeitoso.

Efetivamente, é possível perceber, através das entrevistas realizadas tanto no Brasil como na França, que muitas mulheres fazem essa divisão do seu próprio corpo a partir do momento em que a função alimentar de seus seios se coloca em evidência, criando assim uma proibição temporal: se os seios "são do bebê", então o marido não pode tocá-los, e isso dura enquanto durar o aleitamento materno. Essa mesma reação pode ocorrer também no homem, pois ele mesmo não "ousa" tocar os seios de sua mulher durante o período do aleitamento. Essa situação pode gerar descontentamento de uma parte e de outra, podendo mesmo afetar a continuidade da amamentação. Um exemplo pode ser visto no caso de Claire, uma professora francesa de 40 anos, que contou sobre a falta que sentia da estimulação dos seus seios durante as relações sexuais, já que estes se tornaram um 'campo proibido' para seu marido durante o tempo em que ela amamentou:

\begin{abstract}
Porque para ele o seio se tornou... pertencia ao bebê. Ele me disse isso, aliás, diversas vezes. Ele me disse: - Por enquanto é dele. E eu protestei porque eu dizia: - Desse jeito, o que você quer? Que eu desmame o bebê?... pra começar a ter... nossa vida sexual habitual? E ele me dizia: - Não, não, não! Você deve amamentar o tempo que é necessário, o tempo que você quiser. Mas é isso... Para ele se tornou: 'O seio é do bebê!' E ele achava esquisito de tocar... algo que pertencia agora ao bebê. Quer dizer, ele não tocava mais os meus seios.
\end{abstract}

Podemos supor que essa frustração no plano sexual tenha influenciado na sua decisão de desmamar mais cedo do que previsto. Embora afirmando desejar amamentar "pelo menos até 8 ou 9 meses" e tendo recorrido com esse objetivo ao apoio da La Leche League France, ${ }^{41}$ Claire iniciou o desmame ao final do quarto mês e desmamou completamente quando o bebê completou seis meses. No seu discurso, no entanto, a questão da sexualidade, que aparece em diversos momentos da entrevista, não é colocada em relação com o desmame. Na verdade, a própria decisão de desmamar desaparece para dar lugar à explicação que coloca o desmame em um plano de exterioridade em relação a ela mesma: "meu filho não quis mais, e também ele estava tendo muitos problemas de alergia" - ela disse.

Cito ainda o caso de Marie, uma jovem mãe francesa, dona de casa, que optou, junto com o marido, por não amamentar porque ele sentia ciúmes dos seios dela. A argumentação usada por ele foi, na verdade, dúbia. Marie lembra que ele insistiu no fato de que queria ter uma 
participação ativa em relação aos cuidados com o filho, incluindo "dar a mamadeira". Mas ele disse também que, ao amamentar, ela acabaria mostrando os seios e ele não se sentiria à vontade em uma situação desse tipo. "Imagina se chega um amigo meu para visitar o bebê e você está na sala amamentando!" E finalmente Marie revelou, um pouco constrangida, que seu marido havia dito que "afinal, os seios são meus e não do bebê".

Muitas mulheres encontrar-se-ão, dessa forma, presas em um conflito entre seu papel de 'boa mãe' e aquele de 'boa mulher'. Poucas mulheres continuarão a amamentar contra a aceitação de seus companheiros. Ir contra o companheiro e continuar a amamentar pode gerar um sentimento de desconforto diante desse tipo de escolha, ou mesmo o temor do seu desamor e da separação. Por outro lado, não amamentar pode gerar uma espécie de culpa em relação ao filho, pois o discurso médico atual, pelo menos no Brasil, aponta a amamentação como sendo fundamental para a saúde do bebê, e nesse sentido ela pode ser percebida por muitas mulheres como uma 'obrigação' de uma 'boa mãe'. E mesmo quando o discurso médico não é tão enfático, como na França, a culpa e o ressentimento podem se estabelecer a partir de outras relações. No caso de Marie, ela me disse com tristeza, enquanto dava mamadeira para o filho: "Repare só: a criança amamentada ao seio olha para a mãe, a criança criada com mamadeira olha para fora."

Alguns informantes falam dessa situação de "tabu do seio materno' como um cuidado de higiene, uma vez que o bebê deverá colocar a sua boca no seio para mamar. Aparentemente esse discurso se afasta da idéia de sacralidade do seio materno. Mas há um detalhe importante para a análise dessa explicação: os entrevistados não consideram jamais a possibilidade de se lavar os seios. Por um lado, isso parece confirmar a existência de uma certa noção da maternidade como algo sagrado, que faz com que tudo o que é ligado à maternidade - como os seios e o leite - sejam por sua vez sagrados também. O uso sexual do seio produziria, nesse caso, uma 'sujeira' ou 'impureza' impossível de ser lavada. Por outro lado, é possível propor uma análise nos termos do incesto de segundo tipo: dois idênticos, pai e filho, colocados em relação através de uma terceira pessoa, cujo seio veicula de um a outro uma substância corporal, no caso a saliva. Uma proposição instigante que será aprofundada na pesquisa ora em curso.

O fato de os seios terem assumido uma forte conotação erótica na sociedade ocidental moderna traz um problema a mais para os casais na solução dessa questão, se considerarmos essa noção de sacralidade da 
maternidade. Durante o aleitamento, os seios são às vezes mais atrativos ainda para alguns homens porque se tornam mais volumosos. Dessa forma, as representações individuais sobre os seios desempenham um papel importante para a sexualidade no período da amamentação. O seio maternal e o seio erótico podem ou não ocupar o mesmo corpo, dependendo da forma como os indivíduos interpretam para si esse complexo sistema simbólico e lidam com ele.

De fato, foi possível encontrar entre meus informantes vários casais para os quais não havia nenhum tabu em relação ao seio materno e, portanto, para eles, os seios eram ao mesmo tempo maternais e sexuais. Mesmo a situação, mais ou menos freqüente, do seio que começa a 'vazar' durante o ato sexual, que para alguns casais é motivo de constrangimento e deserotização imediata, para outros é fonte de novos jogos eróticos. Como escreveu Christelle, estudante de antropologia, ao participar de uma discussão sobre esse assunto em uma lista francesa de discussão na Internet sobre aleitamento materno:

Pois é... Cada casal e sua sexualidade é único, porque para nós, esses "jatos" de leite inesperados ou provocados durante as relações sexuais são fonte de uma intensa excitação... Depois que eu amamento, meus seios se tornaram muito mais erógenos para nós dois que antes, principalmente quando eles estão cheios!

E ela assina sua mensagem da seguinte maneira: "Christelle, mamãe de Pierre, e que administra muito agradavelmente a dupla função alimentar e erótica de seus seios..." Do mesmo modo, Adriana, terceiro grau incompleto (pedagogia), carioca, 36 anos, relata que seus seios durante o período da amamentação eram um forte atrativo erótico para seu esposo: "aqueles peitos enormes, aquilo mexia com ele demais! Então a libido aumentou muito entre a gente."

Esses exemplos mostram a coexistência de diferentes atitudes em relação ao dualismo seio materno/seio erótico durante a amamentação e permitem pensar que a sexualidade do casal pode ser um fator importante na determinação da duração do aleitamento materno.

\section{O tabu do incesto}

Como já foi dito, a amamentação pode ser uma experiência sensual. Nesse sentido, o conflito entre seio erótico e seio maternal, e o medo diante do tabu do incesto, são bem presentes no discurso de algumas das mulheres entrevistadas. Na sociedade ocidental moderna o orgasmo é uma experiência muito valorizada; em contrapartida, é uma experiência bem localizada no ato sexual. Ter prazer 
no momento da mamada, com seu bebê ao seio, é percebido por muitas mulheres como uma perversão, um perigo. Certas mulheres vivem essa situação como um verdadeiro problema e se sentem inquietas diante das sensações que experimentam. Cito aqui, como exemplo, a mensagem que Valéria deixou em um fórum de discussão de um site brasileiro sobre aleitamento materno:

Gostaria de compartilhar este assunto com alguém mas, por ser um pouco constrangedor para mim e por não ter uma amiga para perguntar, resolvi aproveitar este espaço. Sempre que amamento meu bebê me sinto estimulada sexualmente. Quando isso ocorre com meu esposo, não me sinto incomodada, pelo contrário. Mas, com meu filho, eu fico completamente transtornada. Peço que alguém que, porventura, tenha vivido algo semelhante, escrevame, pois não sei se isso pode acontecer ou se tenho algum problema e devo procurar ajuda profissional. Obrigado a todas!

Esse apelo recebeu a seguinte resposta de uma psicóloga que assinou Célia:

Acho isso normal. Afinal os seios são zonas erógenas e por isso nos proporcionam sensações sexuais bastante prazerosas. Estou grávida do meu primeiro filho e sou psicóloga também. Acredito que nem tudo é sacrifício na amamentação, ela também deve ser uma fonte de prazer. Então tira as "neuras" da cabeça e curta esse período com descontração. Boa Sorte!

Chama a atenção o fato de que existe um real constrangimento diante dessa situação, tornando mais fácil buscar ajuda em um fórum de discussão na Internet, onde o anonimato é possível, já que grande parte dos usuários se apresentam com pseudônimos. E mesmo que a pessoa se apresente com seu nome verdadeiro, o distanciamento proporcionado pelo espaço virtual reduz a percepção de exposição de si mesmo. Esse constrangimento apareceu também em situações de entrevista durante esta pesquisa, sendo o tabu do incesto um tema que aparece mais nas hesitações, nos lapsos, nos silêncios, nos 'não-ditos'. Por isso considero essa mensagem na Internet, esse pedido de ajuda, ainda que oriundo de um espaço virtual, bastante revelador de uma realidade vivida e, em alguns casos, sofrida por diversas mulheres.

É interessante a forma como algumas mulheres falam de "prazer" para descrever suas sensações durante as mamadas, mas se apressam em fazer uma diferenciação entre esse prazer da mamada e o prazer sexual: "Não é um prazer sexual!". Em seguida, muitas dentre elas afirmam saberem que algumas mulheres sentem um prazer sexual no aleitamento, "mas eu não!". Efetivamente, não são todas 
as mulheres que sentem prazer sexual na mamada. O prazer por elas referido pode ser de uma outra ordem, em geral ligado a todo um contexto de experiência da maternidade desejada, como pude depreender do discurso de várias mulheres. Em algumas entrevistas, porém, esta seqüência (tenho prazer - não é sexual - sei que existe - eu não!) é acompanhada de lapsos na fala ao se descrever as sensações no momento da mamada, como é o caso de Adelaide, uma advogada brasileira de 39 anos, que chegou a começar a dizer a palavra orgasmo ao descrever o prazer da mamada quando seus seios estão cheios de leite. Podemos supor que, nesse caso, a percepção do 'risco' do incesto é presente, a partir da análise de dois detalhes do discurso. Em primeiro lugar, existe subjacente uma preocupação em afastar a idéia mesmo da existência de um prazer sexual incestuoso, quando ela imediatamente define seu prazer como não sexual, uma questão sobre a qual outras mulheres não fazem qualquer referência. Uma segunda questão se refere ao lapso em relação à descrição do prazer, que sugere uma dificuldade de dizer algo que pode estar sendo fonte de um mal-estar. A ocorrência desses dois detalhes no mesmo discurso é bastante sugestiva, em especial se considerarmos a permeabilidade desse grupo de informantes aos discursos médico e psicológico.

Mas existem também os casos em que, embora presente a princípio, esse medo do tabu do incesto é bem resolvido pelo casal e, nesses casos, falar sobre o assunto não causa maiores constrangimentos. É o caso de Adriana, que começa assim a descrição de suas sensações durante as mamadas:

No começo foi muito difícil. Porque mexe muito com a coisa da sexualidade, né. Você tem uma criança... Falando muito assim, cruamente, você tem uma criança lambendo... porque pára de sugar, daqui a pouco ela passava aquela linguinha... eu tinha... eu tinha... ondas, né, de prazer enorme, assim...

Questionada sobre a semelhança dessa sensação a um orgasmo, Adriana não hesitou:

Como um orgasmo! E era uma coisa difícil de relacionar com a amamentação, com a maternidade. Quer dizer, então... Não era um ato sexual! Eu não estava transando com meu marido, eu não estava fazendo amor com alguém! A minha filha mamava em mim e aquilo me causava prazer. Então no começo foi muito difícil. Aceitar aquilo. A impressão que dava era aquela coisa: - Gente, que coisa imoral! Sabe? Mas... com o passar do tempo a gente viu que aquilo era uma coisa absolutamente normal. Eu fui trabalhando aquela coisa da sexualidade muito bem. (...) No começo, como eu te falei, foi uma coisa assim, que 
assustou... Né? Uma coisa meio que... Ah! A Igreja! Diz o quê? O quê que é o ensinamento?... Essa coisa toda. Bateu muito... muito chocante pra gente! Mas como a gente foi trabalhando junto, né... Meu marido... Ele sempre esteve ali do meu lado, trabalhando comigo. Então não foi difícil a gente trabalhar esse momento.

A relação entre a amamentação e a sexualidade feminina pode se ligar ao medo do tabu do incesto e a partir daí, como vimos, tomar vários caminhos possíveis nas experiências individuais. Algumas mulheres, como Adriana, depois de resolverem em suas mentes essa 'culpa' do incesto, se apropriam desse prazer físico que proporciona a amamentação e aproveitam para ter momentos de intimidade com o marido logo após a mamada, momento em que elas estariam já sexualmente estimuladas. Outras mulheres para as quais esse conflito se apresenta se recusam a ouvir o seu corpo e negam suas sensações ou as nomeiam de outra forma para que elas percam seu sentido original, permitindo assim prosseguir o aleitamento materno. Há ainda aquelas, como Sylvie, para quem o prazer que elas sentem com o bebê parece tão completo que têm dificuldade de reiniciar a vida sexual com 0 companheiro enquanto amamentam. E finalmente podemos imaginar que existem as mulheres que, sentindose culpadas diante de um suposto ato incestuoso, recusam a continuidade da amamentação. Nesse caso, pode-se supor que as 'razões' explicitadas para o desmame distanciar-se-ão do campo da sexualidade e do tabu do incesto.

Mas o tabu do incesto não aparece apenas no discurso feminino. Alguns de meus informantes homens também fazem referência a ele, mas de uma outra forma, menos direta. Para eles, o fato de sua mulher se tornar mãe modifica completamente o olhar que eles têm sobre elas. A mulher deixa de ser 'mulher' e se torna 'mãe', lugar de muitas fantasias e tabus. Eles usam freqüentemente a palavra 'respeito' ao definir esse novo olhar e o sentimento que ele evoca. Um respeito que se traduz algumas vezes por um 'não-desejo'. A presença dessa noção de respeito sugere uma análise que se situa no campo psicanalíico. Estariam estes homens temerosos de reencontrar sua própria mãe na pele de sua esposa que amamenta? Parece ser este o caso de Celso quando ele diz, a respeito da sexualidade do casal durante a amamentação:

Não, aí não! Depois que... no tempo em que ela estava amamentando, essa coisa de... de ter uma intimidade maior, de experimentar o leite lá do seio dela, essas coisas não. Eu não quis tocar. (...) Eu via ela muito como mãe. Estava aquela mãe intensa. Então talvez até viesse essa 
${ }^{42}$ A esse respeito ver, por exemplo, Sarah MOSKO, Christopher RICHARD, James MCKENNA, Sean DRUMMOND e David MUKAI, 1997. Ou ainda Roger W. BYARD e Henry F. KROUS, 2001 coisa... do papel de mãe ser tão forte aí que ficou uma coisa pra mim meio sagrada, meio intocável, né. Ficou meio sagrado, no altar aquele negócio ali... Num pedestal. Eu não quis me aproximar não.

Efetivamente, segundo seu relato, o casal só voltou a se reencontrar sexualmente quando ela parou de amamentar, aos três meses do bebê. E ele finaliza dizendo: "quando aquela grande mãe esvaziou um pouco, começou a ter espaço também..." Esta sua última frase me faz pensar nas palavras de um outro brasileiro, Álvaro, 34 anos, engenheiro eletricista, que, embora tendo retomado sua vida sexual com sua esposa após o nascimento da filha, sentia-se incomodado, chegando mesmo a pedir à sua esposa que parasse de amamentar, o que ela só fez quando a filha tinha 1 ano e 4 meses. Ele me disse o seguinte: "A mulher só volta a ser completamente mulher depois que pára de amamentar".

Uma outra possibilidade de análise, no entanto, se insere no campo antropológico e diz respeito à argumentação héritiana do incesto de segundo tipo, já referida anteriormente. Nesse caso, o tabu do incesto não se referiria a um fantasma da mãe: o homem e a imagem simbólica da sua própria mãe, presente na sua mulher, colocados em relação. $O$ incesto se concretizaria através do uso sexual do seio materno e das substâncias por ele veiculadas, que colocariam pai e filho em relação. Seria esse talvez o "ato contra a natureza" de que fala Béatrice em uma mensagem recolhida em uma lista de discussão francesa sobre amamentação. Ela descreve assim a reação do seu marido em relação à vida sexual do casal durante o período de amamentação:

De imediato, meus seios se tornaram 'reservados ao bebê' totalmente e, se ele os tocava, sua boca os evitava totalmente. Ele achava estranha a idéia de atribuir uma função diretamente sexual a um elemento 'maternante' do meu corpo. Um tipo de ato contra a natureza, um incesto, sei lá...

\section{O 'sono compartilhado'}

Essa expressão refere-se à prática de colocar o bebê para dormir junto com os pais (ou apenas junto com a mãe) no leito conjugal. Muitos autores na área médica afirmam que o 'sono compartilhado' é importante para a saúde do bebê, podendo mesmo representar uma segurança contra a morte súbita do bebê ou 'morte no berço'. ${ }^{42}$ Por outro lado, essa prática pode trazer problemas para a relação do casal. Tema de conflito, o "sono compartilhado" se associa a outra questão muito interessante, que aparece 
43 fato de trabalhar com a classe média talvez explique em parte esse achado. É possível que a prática de dormir na mesma cama com os filhos, no caso do Brasil, seja mais encontrada nas favelas ou bairros populares, porém a motivação para fazê-lo será provavelmente diferente daquela que se observa entre minhas informantes francesas.

44 'Transtornar', segundo o dicionário Aurélio: alterar a ordem de; perturbar, atrapalhar; agitar. de formas diferentes em muitas entrevistas, mas que não é alvo de maiores considerações neste artigo: o aleitamento e o cuidado do bebê dentro de um contexto de 'retorno à natureza'.

Entre meus informantes brasileiros, foram poucos os casos em que a mãe dizia adotar essa prática de dormir com seu bebê. ${ }^{43} \mathrm{Na}$ França, por outro lado, mesmo se o aleitamento materno não aparece como uma prática habitual, entre as mães que eu entrevistei e que efetivamente amamentavam, muitas eram aquelas que praticavam o 'sono compartilhado'. Em alguns casos, fazemse arranjos na arrumação do quarto, incluindo um colchão ou uma cama pequena ao lado da cama do casal, ou mudando a disposição dos móveis de forma que a cama fique contra a parede, impedindo o bebê de cair acidentalmente. Em outros, o bebê é simplesmente colocado na cama, entre o casal. Nesse caso, o bebê acaba por se tornar uma espécie de barreira física entre o homem e a mulher, situação ao mesmo tempo concreta e simbólica do transtorno ${ }^{44}$ que a chegada de um bebê pode representar na vida de um casal. Na verdade, segundo meus informantes, não são raros os homens que, incomodados com essa situação, "desertam do leito conjugal" (e aqui eu utilizo a expressão de um informante francês) e vão dormir no sofá da sala ou em outro quarto, enquanto a mãe dorme com o bebê. Como François, que contou que fazia já três meses que ele dormia no sofá da sala.

É possível imaginar que situações desse tipo engendrem conflitos mais ou menos importantes para o casal. E de fato encontrei entre meus informantes um caso em que a mulher - Marta, brasileira, 38 anos, analista financeira - identifica claramente a presença da filha dormindo com ela como uma das razões que levaram à separação do casal. Ela conta:

Um dos motivos também, que gerou a nossa separação, foi, é... a Elisa estar sempre... [na cama] e eu deixar. Que eu acabava deixando. Isso incomodou muito ele, incomodou bastante. Muitas vezes ele falava. Eu tentava, mas... (...) Mas que atrapalha, atrapalha mesmo. Com certeza. Até mesmo pra você ficar mais à vontade na cama, né. No espaço físico. Mas eu só fui... A gente só vai perceber quando o negócio já está mais embolado, né...

\section{Considerações finais}

A comparação das práticas de diferentes sociedades nos leva a questionar a nós mesmos, nossas práticas, nossas representações. Como vimos no início deste 
artigo, a relação entre amamentação e sexualidade é importante em diversas sociedades, dando origem a tabus e costumes os mais variados. A análise das entrevistas com brasileiros e franceses é reveladora da presença igualmente, para os dois grupos de informantes, de tabus quando estas duas práticas - sexualidade e amamentação - são colocadas em relação. A despeito das especificidades culturais do Brasil e da França, observa-se uma convergência das experiências e dos discursos, através dos quais é possível destacar dois pontos que se entrecruzam e que nos permitem propor uma reflexão sobre a questão das relações entre sexualidade e amamentação nas sociedades ocidentais contemporâneas: a concepção da maternidade, com tudo que ela envolve, como algo sagrado, ao contrário do sexo, que é concebido como impuro; e o valor erótico, sexual, atribuído aos seios.

A representação da maternidade como sendo sagrada permanece no imaginário social, a despeito da revolução dos costumes trazida pelo feminismo no Ocidente. Por outro lado, o erotismo atribuído aos seios e uma certa percepção do corpo como instrumento para o prazer tendem a ser cada vez mais valorizados nas sociedades ocidentais. Nesse sentido, as mudanças corporais da mulher que se torna mãe e sua ligação especial com o bebê durante o período da amamentação podem ser vividas pelo casal diferentemente, de acordo com a maneira com que cada um lida com tais representações. A impossibilidade de que a 'mãe' e a 'mulher' convivam no mesmo corpo, seja na percepção do homem, seja na da própria mulher, pode gerar uma situação conflituosa para o casal, com repercussões na sexualidade. Pode ainda repercutir na relação com o bebê e, em especial, na duração do aleitamento materno. Um conflito desse tipo, que muitas vezes não passa pelo consciente, pode explicar a persistência, em várias mulheres, de um discurso sobre o desmame que coloca a responsabilidade do fim da amamentação no bebê: "Ele [o bebê] largou o peito, não quis mais.". Uma fórmula eficaz de evitar o questionamento de si mesma e do casal. O nascimento de um filho e a passagem para a dimensão de 'pais' é um fator reconhecido por diversos autores como tendo um efeito sobre a sexualidade do casal. O aleitamento materno pode, como vimos, intensificar tais mudanças, por trazer inúmeros conflitos nos planos psicológico e relacional. O reconhecimento de tais questões é o primeiro passo que nos permitirá, não resolver esses conflitos, mas melhor trabalhar com eles.

O aleitamento materno é um tema de grande complexidade. O que foi apresentado aqui - a relação 
entre amamentação e sexualidade - representa apenas um dos caminhos possíveis de estudo deste tema. Algumas possibilidades de análise antropológica foram aqui sugeridas e deverão ser aprofundadas no âmbito desta pesquisa. Mas o aleitamento materno se coloca como um tema instigante e um campo de pesquisa estimulante do ponto de vista de uma abordagem antropológica.

\section{Referências bibliográficas}

ALTORKI, Soraya. "Milk-kinship in Arab Society: an Unexplored Problem in the Ethnology of Marriage." Ethnology, Tome XIX, 1980. p. 233-244.

ARISTOTE, De la génération des animaux. Paris: Les Belles Lettres, 1961.

BADINTER, Elisabeth. L'amour en plus: histoire de l'amour maternel (XVII $-X X^{e}$ siècles). Paris: Flammarion, 1980.

BLEDSOE, Caroline. Side-stepping the Post-partum Sex Taboo: Mende Cultural Perceptions of Tinned Milk in Sierra Leone. Paper presented for the Rockefeller Conference on the Cultural Roots of African Fertility Regimes, February 25-March 1st., 1987, Ife, Nigeria.

BOLOGNE, Jean-Claude. Histoire de la pudeur. Paris: Olivier Orban, 1986.

BONNEMÈRE, Pascale. "Considérations relatives aux représentations des substances corporelles en NouvelleGuinée". L'Homme, 114, p. 101-120, avril-juin, 1990.

BONTE, Pierre. "Le sein, l'alliance, l'inceste". Autrement - Série Mutations/Mangeurs (Mémoires lactées - blanc, bu, biblique : le lait du monde), Paris, n. 143, p. 143-156, 1994.

BYARD, Roger W., and KROUS, Henry F. (eds.). Sudden Infant Death Syndrome: Puzzles, Problems, Possibilities. London: Arnold Publishing, 2001.

DES-ESSARTZ, Jean-Claude. Traité de l'éducation corporelle des enfants en bas âge. $2^{\mathrm{e}}$ éd. Paris, 1799.

FINE, Agnès. "Le lait 'contrarié'”. Autrement-Série Mutations/ Mangeurs (Mémoires lactées - blanc, bu, biblique : le lait du monde), Paris, n. 143, p.157-170, 1994.

FLANDRIN, Jean-Louis. Le sexe et l'Occident: évolution des attitudes et des comportements. Paris: Seuil, 1981.

FORD, Clellan S., and BEACH, Frank A. Patterns of Sexual Behavior. New York: Harper and Brothers, Hoeber Medical Division, 1951.

FREUD, Sigmund. Três ensaios sobre a teoria da sexualidade. Rio de Janeiro: Imago, 1997.

FREYRE, Gilberto. Casa Grande e Senzala: formação da família brasileira sob o regime da economia patriarcal. Rio de Janeiro: José Olympio, 1978. 
GODELIER, Maurice. La production des grands hommes: pouvoir et domination masculine chez les Baruya de Nouvelle-Guinnée. Paris: Fayard, 1982.

HAVELOCK, Ellis. Studies in the Psychology of Sex. Philadelphia, F. A. Davis Co., 1913. v. III: Analysis of the Sexual Impulse: Love and Pain, The Sexual Impulse in Women.

HERDT, Gilbert. "Semen Transactions in Sambia Culture." In: HERDT, G. (ed.). Ritualized Homosexuality in Melanesia. Berkeley: University of California Press, 1984. p. 167-210.

HÉRITIER, Françoise. "Identité de substance et parenté de lait dans le monde arabe". In : BONTE, P. (ed.). Épouser au plus proche: inceste, prohibitions et stratégies matrimoniales autour de la Méditerranée. Paris: Éditions de l'EHESS, 1993. p. 149-164.

. Les deux sœurs et leur mère: anthropologie de l'inceste. Paris: Odile Jacob, 1994.

LIONETTI, Roberto. Le lait du père. Paris: Imago, 1988.

MAGALHÃES, Elizabeth K. C.; GIACOMINI, Sonia Maria. "A escrava ama-de-leite: anjo ou demônio?" In: BARROSO, C.; COSTA, A. O. (Orgs.). Mulher, mulheres. São Paulo: Cortez/Fundação Carlos Chagas, 1983. p. 73-88.

MEGALE, Nilza Botelho. Invocações da Virgem Maria no Brasil. Rio de Janeiro: Vozes, 1998.

MOSKO, Sarah, RICHARD, Christopher, MCKENNA, James, DRUMMOND, Sean, and MUKAI, David "Maternal Proximity \& Infant CO2 Environment During Bedsharing \& Possible Implications for SIDS Research." American Journal of Physical Anthropology, n. 103, 1997, p. 315-328.

PASINI, Willy; ABRAHAM, George. Introduction à la sexologie médicale. Paris: Payot, 1974.

RIBEIRO, Darcy. Diários índios: os Urubus-Kaapor. São Paulo: Companhia das Letras, 1996.

ROLLET, Catherine; MOREL, Marie-France. Des bébés et des hommes: traditions et modernité des soins aux tout-petits. Paris: Éditions Albin Michel, 2000.

SHORTER, Edward. A formação da família moderna. Lisboa: Terramar, 1995.

SILVA, Antônio Augusto Moura da. Amamentação: fardo ou desejo?: estudo histórico-social dos saberes e práticas sobre aleitamento na sociedade brasileira. 1990. Dissertação (Mestrado em Medicina Social) - Faculdade de Medicina, USP, Ribeirão Preto.

THIS, Bernard. "Cachez ce sein que je ne saurais boire!" In : HERBINET, Etienne (Dir.). D'amour et de lait...Les Cahiers du Nouveau-né 3. Paris: Stock, 1980. p. 115-127.

WAGNER, Roy. "The Ends of Innocence: Conception and Seduction among the Daribi of Karimui and the Barok of New Ireland." Mankind, v. 14, n. 1, 1983. p. 75-83. 
[Recebido em julho de $2002 \mathrm{e}$ aceito para publicação em julho de 2003]

\section{Breastfeeding and Sexuality}

Abstract: The present article deals with breastfeeding and its relation with sexuality in an anthropological approach, based on interviews carried out with men and women in Brazil and France. In modern occidental society, double function of breast - maternal and erotic -, as well as representations that man and woman have of the maternity, come out as the base for important alterations in couple sexuality during the breastfeeding period. As maternal milk has a strong symbolic meaning in different cultures, breastfeeding goes beyond biological and nutritional contexts. Among others corporal substances, milk has an important role in the representations of the body, originating blood relations and interdictions in different societies. The analysis of Brazilian and French interviewees discourse reveals also the presence of some taboos when these two practices - sexuality and breastfeeding - are taken into consideration. The reflection on this matter is essential for the discussion of man-woman relations in the current Brazilian breastfeeding incentive context.

Key words: breasffeeding, sexuality, maternity, man-woman relations. 